\title{
Tilletia barclayana: biologia e manejo em arroz irrigado
}

\author{
Tilletia barclayana: biology and management in irrigated rice
}

\author{
Carla Rejane Zemolin ${ }^{I^{*}}$ Ivan Dressler da Costa $^{\mathrm{I}}$ Giuvan Lenz $^{\mathrm{I}}$ Leandro Marques $^{\mathrm{I}}$ \\ Maurício Stefanelo ${ }^{\mathrm{I}}$ Douglas Karkow ${ }^{\mathrm{I}}$ Adriano Arrué ${ }^{\mathrm{I}}$ Cézar Coradini $^{\mathrm{I}}$ Tânia Bayer $^{\mathrm{I}}$
}

\section{- REVISÃO BIBLIOGRÁFICA -}

\section{RESUMO}

A cárie-do-arroz (Tilletia barclayana), doença considerada secundária na cultura do arroz irrigado, vem ganhando importância nos últimos anos devido aos níveis elevados de infestação e à redução do rendimento. A doença é favorecida por temperatura e umidade do ar elevadas, doses altas de nitrogênio e semeadura tardia. Para o manejo, recomenda-se uso de resistência varietal, semeadura na época recomendada e adubação equilibrada.

Palavras-chave: Oryza sativa, cárie-do-arroz, Tilletia barclayana.

\section{ABSTRACT}

The rice kernel smut (Tilletia barclayana), which is considered as a secondary disease, lately has been growing in importance due to its high infestation levels and effects in seed yield. This disease is favored by elevated air temperatures and humidity; high nitrogen fertilizer rates a late sowing. In order to control it, the use or resistant varieties, appropriate sowing dates and balanced fertilization of the soil, are recommended practices.

Key words: Oryza sativa, kernel smut of rice, Tilletia barclayana.

\section{INTRODUÇÃO}

O arroz é um dos principais componentes da dieta do brasileiro. A região Sul do Brasil é uma importante região orizícola. Na última safra (2006/2007), por exemplo, a região foi responsável pela produção de 7.560.895 toneladas, e o Rio Grande do Sul (RS) foi responsável por 6.419.300 toneladas de grãos em uma área de 954,4 mil ha (IBGE, 2008).

Essa produtividade poderia ser ainda maior, porém alguns fatores limitam a obtenção de maiores valores. Dentre eles, encontram-se as doenças, as quais incidem na cultura do arroz irrigado e provocam perdas na produtividade das lavouras. Dentre essas doenças, tem se destacado a cárie-do-arroz, a qual ataca as panículas do arroz irrigado. Estudos da situação da cárie-do-arroz indicam que, embora ainda considerada uma doença secundária, essa doença tem ganhado importância nos últimos anos (RAM et al., 1998). Perdas de 10 a $40 \%$ na produtividade da cultura foram observadas em experimentos conduzidos na safra 2004/ 05(COSTA et al., 2006). Essa doença também ocasionou danos na cultura do arroz irrigado no Estado do Rio Grande do Sul, na safra 2005/06, causando perdas de até $40 \%$ em rendimento e qualidade de grãos principalmente em cultivares como 'IRGA 417' e ‘IRGA 422CL'(CARTWRIGHT et al., 1996; COSTA et al., 2006).

A cárie-do-arroz é uma doença de ocorrência frequente nos países da Ásia, no Sul dos Estados Unidos e no Brasil. No Brasil, a presença desse fungo

IDepartamento de Defesa Fitossanitária, Centro de Ciências Rurais (CCR), Universidade Federal de Santa Maria (UFSM), 97105900, Santa Maria, RS, Brasil. E-mail: carlazemolin@yahoo.com.br. *Autor para correspondência. 
já foi verificada nos Estados do Ceará, Rio de Janeiro e Rio Grande do Sul. No entanto, nos dois primeiros Estados, a ocorrência é menos pronunciada que no Rio Grande do Sul, onde esse fungo teve ocorrência praticamente em todas as áreas produtoras de arroz irrigado nas últimas safras (Del PONTE 2008; COSTA et al., 2006).

A presente revisão tem como objetivo descrever a biologia e o manejo da cárie-do-arroz na cultura do arroz irrigado, visando disponibilizar mais informações para a redução das perdas causadas por esse patógeno.

\section{Biologia do fungo Tilletia barclayana}

O agente causal da cárie-do-arroz foi inicialmente nomeado como Tilletia horrida por TAKAHASHI (1896). Posteriormente, PADWICK \& KHAN (1944) classificaram o fungo como sendo Neovossia horrida. DURAN \& FISCHER (1961) estudaram a citologia da germinação e do desenvolvimento de teliósporos do fungo e o chamaram de Tilletia barclayana, que foi confirmado por PIMENTEL et al. (1998) com análises por meio de PCRRFLP. Atualmente, Tilletia barclayana é usado para descrever o agente causal da cárie-do-arroz.

Tilletia barclayana, de acordo com CASTLEBURY et al. (2005), é um fungo pertencente ao grupo dos Basidiomicetos, da ordem Tilletiales e do gênero Tilletia. Esse patógeno normalmente forma esporos como teliósporos e basidiósporos e desenvolve micélio monocariótico (primário) e dicariótico (secundário). Formam também estruturas do tipo soro, o qual contém os teliósporos (BEDENDO, 1995).

Os teliósporos são unicelulares e binucleados, possuem forma arredondada medindo 1823 $\mu$ m de diâmetro, parede celular compacta (CARRIS et al., 2006), podendo ser lisa ou ornamentada (BEDENDO, 1995), às vezes, apresentando curto apêndice hialino densamente coberto por espículos pontiagudos (WEBSTER \& GUNNELL, 1992). Os teliósporos suportam grandes variações no $\mathrm{pH}$, na temperatura do ar e na umidade do solo. Sua germinação é muito baixa e, após 12 meses, essa germinação raramente excede 50\%, com 15 a 30\% em média. Esse tipo de dormência contribui para a sobrevivência do esporo sob condições de campo (12 a 24 meses) (COSTA \& LENZ, 2006).

Para que os teliósporos tenham boa germinação, é necessário passar por um período de pós-maturação, uma fase de descanso (cinco a seis meses), uma hidratação sob regime de luz e um suprimento adequado de oxigênio (OU, 1985; LIANG et al., 1996; LIANG et al., 2003). De acordo com LIANG et al. (2003), os teliósporos de $\boldsymbol{T}$. barclayana germinam sob incidência de luz, a qual tem duplo efeito na estimulação pós-maturação e na germinação dos teliósporos.

Segundo BEDENDO (1995), os basidiósporos são ovalados, unicelulares, uninucleados, hialinos, normalmente não existem ornamentações e são produzidos a partir da germinação dos teliósporos, os quais dão origem a um pró-micélio (tubo germinativo) que se diferencia numa basídia. No caso da família Tilletiaceae, a basídia é asseptada, e os basidiósporos são formados em tufos, situados na extremidade da basídia. Os basidiósporos podem se reproduzir por brotamento ou germinar formando uma hifa e produzir um micélio primário, o qual é monocariótico e não possui capacidade de colonizar plantas hospedeiras. A união de dois micélios primários (plasmogamia) dá origem ao micélio secundário (dicariótico), o qual tem a capacidade de penetrar e colonizar o tecido do hospedeiro sem a formação de haustórios. É esse micélio que, no final do processo, fragmenta-se e produz novamente os teliósporos.

A germinação não é afetada por diferentes soluções de nutrientes e tem sua faixa ótima de crescimento com temperatura de $30^{\circ} \mathrm{C}$ (OU, 1985). Segundo SINGH (1975), a incidência de T. barclayana é favorecida por solos arenosos, chuvas freqüentes, alta luminosidade e umidade relativa do ar e temperatura de 25 a $30^{\circ} \mathrm{C}$ no período de antese.

Cada grão pode produzir até 37,5 mil teliósporos, os quais sobrevivem no solo, na palha ou na água, entre os cultivos de arroz irrigado e podem ser disseminados pelo vento, infectando as panículas no ano seguinte (Del PONTE, 2008). Singh \& Pavgi (1973), apud OU (1985), descreveram o ciclo de vida de $\boldsymbol{T}$. barclayana. Eles relataram que o basidiósporo secundário se aloja primeiramente no estigma, penetra no estilete, alcançando o ovário e permanece entre a camada de aleurona e as películas do grão, digerindo o endosperma.

As panículas infectadas emergem com aspecto normal (RODRIGUEZ, 1995), e os sintomas aparecem na fase de maturação do arroz e são constatados com maior facilidade nas manhãs úmidas. A massa de esporos absorve água e aumenta o volume do grão, tornando-se visível e cobrindo outras partes da planta com líquido preto. Durante o dia a massa se desidrata, tornando-se pó negro, o qual é facilmente removido das plantas e pode formar poeira que cobre as colhedoras de preto, estes são teliósporos em massa (Del PONTE, 2008). A doença se manifesta em apenas alguns grãos da panícula e, frequentemente, só em parte 
destes (PADWICK, 1950) e não há evidências de produção de toxinas pelo fungo (COSTA \& LENZ, 2006).

Para que ocorra a infecção, as condições ambientais devem ser favoráveis no momento da fecundação da semente do arroz, ou seja, temperatura entre 24 e $30^{\circ} \mathrm{C}$ e umidade relativa do ar superior a $85 \%$ (CARRIS et al., 2006), também sendo necessária a presença de propágulos infectivos (basidiósporos) para que se inicie o processo de infecção.

O patógeno pode desenvolver-se nas sementes de arroz e diversas gramíneas, principalmente do gênero Brachiaria, Digitaria, Echinochloa e Pennisetum (RIBEIRO, 1985). A infecção ocorre principalmente em Poáceas (RODRIGUEZ, 1995), de maneira localizada (CARRIS et al., 2006), num curto período de tempo, na antese, isto é, logo após emissão da panícula, na abertura do pálea e da lema (casca do grão de arroz), quando ocorre a liberação da antera e a fecundação da semente (RODRIGUEZ, 1995). Massas de esporos que substituem o endosperma da semente são liberadas antes ou durante a colheita e contaminam os grãos sadios, os restos de palha e o solo. Na safra seguinte, com a entrada da água na lavoura, os esporos germinam na superfície da água, dando origem aos esporos primários. Estes são liberados do prómicelio para formar grande número de esporos secundários, os quais são liberados no ar para infectar os ovários em desenvolvimento nas panículas de arroz quando as flores estiverem abertas (TEMPLETON, 1961; WEBSTER \& GUNNELL, 1992).

Fatores que interferem no progresso da doença A cárie-do-arroz é uma doença difícil de ser manejada, uma vez que sementes infestadas pelo fungo, semeadura tardia e doses excessivas de nitrogênio favorecem o desenvolvimento do patógeno. Dessa forma, o manejo deve ter como base o uso de doses racionais de nitrogênio, cultivares resistentes, sementes isentas do patógeno e semeadura na época recomendada (JISKANI, 2001).

\section{Nitrogênio}

Dos nutrientes essenciais às plantas, o nitrogênio $(\mathrm{N})$ está entre os requeridos em maior quantidade, sendo considerado um importante fator para determinar o potencial de produção do arroz irrigado (MARUMOTO, 1986). O nitrogênio é responsável pelo aumento da área foliar da planta, o que aumenta a eficiência de interceptação da radiação solar, da taxa fotossintética e, consequentemente, da produtividade de grãos (FAGERIA \& SANTOS, 2004). Porém, quando ocorrem inadequações quanto à dose e época de aplicação do N, além de reduzir a produção, há aumento da incidência de doenças na cultura (FAGERIA et al., 1997), uma vez que certos patógenos incidem severamente em plantas subnutridas, enquanto outros preferem plantas vigorosas. De modo geral, teores elevados de nitrogênio tendem a aumentar a suscetibilidade das plantas às doenças (KRUGNER, 1978).

Dentre essas doenças, a cárie-do-arroz vem ganhando importância, uma vez que provoca perdas significativas de produtividade. No Arkansas (EUA), a severidade em lavouras comerciais foi influenciada principalmente pela fertilização excessiva de nitrogênio em cultivares como 'Cipreste' e 'LaGrue', que apresentam grão longo (CARTWRIGHT et al., 1996).

Normalmente, quando T. barclayana estiver presente, é encontrada em plantas mais vigorosas (ATKINS, 1974), uma vez que estudos têm demonstrado que o uso de excessivas doses de $\mathrm{N}$ tem aumentado a incidência e a severidade da cárie-do-arroz (TEMPLETON, 1963; KUMAR et al., 1978; SHARMA et al., 1999; SLATON et al., 2001), bem como de outras doenças do arroz irrigado (GROTH \& LEE, 2002). TEMPLETON (1963) constatou que o grau de infecção por T. barclayana em algumas cultivares (expressa pelo número de grãos cariados por 100 gramas de sementes) correlaciona-se diretamente com o aumento da dose de nitrogênio. TEMPLETON (1967) observou casos mais severos de cárie-do-arroz em lavouras cultivadas previamente com leguminosas por um período de um a dois anos e que receberam doses de nitrogênio iguais ou superiores a $100 \mathrm{~kg} \mathrm{ha}^{-1}$.

O trabalho de KUMAR et al. (1978) mostrou diferenças significativas entre 17 cultivares de arroz, cultivadas com altas e baixas doses de NPK, no número de grãos por planta e na porcentagem das panículas afetadas por T. barclayana, e as cultivares que receberam doses mais elevadas também apresentaram maior número de grãos cariados por planta e maior porcentagem de panículas com sintomas da doenças. Estudos realizados por SLATON et al. (2004) mostraram que a severidade da cárie-do-arroz foi diminuída em até $50 \%$ quando a dose de $\mathrm{N}$ passou de $152 \mathrm{~kg} \mathrm{ha}^{-1}$ para $84 \mathrm{~kg} \mathrm{ha}^{-1}$.

\section{Resistência genética}

O método mais prático e econômico para controlar as doenças das plantas consiste na semeadura de cultivares mais resistentes ou tolerantes, mas isso se torna difícil devido à reduzida variabilidade de germoplasma de arroz usada atualmente (SOSBAI, 2005). Para o Brasil, não existem estudos de reação de germoplasma de arroz com relação à T. barclayana. 
Cultivares de arroz irrigado diferem quanto à suscetibilidade à $\boldsymbol{T}$. barclayana, mas, em geral, cultivares de grão curto são mais resistentes que cultivares de grão médio e longo (CARRIS et al., 2006). O grau de suscetibilidade parece estar correlacionado, em parte, com a duração da antese e o diâmetro da abertura da flor, e o diâmetro da abertura floral é maior para cultivares de grão longo e menor para cultivares de grão médio e curto (COSTA \& LENZ, 2006).

Estudos realizados por CHAHAL et al. (2003) e PAN et al. (1995) mostraram que há uma correlação positiva entre a duração da abertura das flores e a incidência e severidade da doença, além de uma correlação negativa entre o número de grãos de pólen e incidência e severidade, uma vez que a incidência e severidade da doença foram máximas nos genótipos que possuem longo período de antese e menor concentração de grãos de pólen.

Época de semeadura

A época de semeadura é outro fator importante no controle das doenças do arroz irrigado (FUNCK, 2008). TEMPLETON et al. (1967) mostraram que a severidade da infecção da cárie-do-arroz em cultivares semeadas mais cedo foi menor em comparação com aquelas semeadas mais tardiamente. Segundo FUNCK (2008), no Rio Grande do Sul, os resultados das pesquisas indicam que o período preferencial de semeadura do arroz irrigado vai de outubro a novembro. A semeadura na época preferencial é importante, uma vez que, em semeaduras mais tardias, a incidência da cárie-do-arroz pode aumentar consideravelmente, já que a cultura fica exposta às condições climáticas favoráveis ao desenvolvimento do patógeno. Resultados de pesquisa obtidos por COSTA et al. (2006) mostraram que a maior incidência de $\boldsymbol{T}$. barclayana foi observada quando a semeadura ocorreu no fim de outubro e início de novembro, na região central do Rio Grande do Sul. Isso se explica pelo fato de que esse patógeno incide sobre as panículas do arroz irrigado no momento da floração, o que ocorre nos meses de janeiro e fevereiro para esse período de semeadura.

TEMPLETON et al. (1967) citam que a época de semeadura exerce principal influência sobre a incidência de $\boldsymbol{T}$. barclayana no que se refere ao fato de que semeaduras precoces, quando comparadas a tardias, proporcionaram diferentes condições climáticas no estádio de antese, o que ocasionou variação de incidência e severidade de até 53\% e 22\%, respectivamente.
Tratamento de sementes

Com relação ao tratamento de sementes, não existem evidências de que este seja efetivo no controle de $\boldsymbol{T}$. barclayana, apesar de o carbonato de cobre em pó, o Formaldeído e os Organo-mercuriais já terem sido usados no passado (REYES, 1933). RODRIGUEZ (1995) relata que fungicidas orgânicos, tais como os Benzimidazóis, são eficazes para erradicar o inóculo da semente. $\mathrm{O}$ tratamento de sementes pode prevenir o surgimento da doença em locais não-infestados e em solos que não tenham inóculo proveniente de safras afetadas recentemente (PADWICK, 1950).

Controle químico

Atualmente, no Brasil, não existem produtos registrados para o controle de $\boldsymbol{T}$. barclayana na cultura do arroz irrigado, embora resultados de pesquisa obtidos por SHARMA et al. (1999) e CARTWRIGHT \& LEE (2001) indiquem que alguns ingredientes ativos fornecem controle parcial sobre a cárie-do-arroz.

Segundo CARTWRIGHT \& LEE (2001), aplicações de Propiconazol no último estádio do emborrachamento são recomendadas para cultivares suscetíveis em lavouras com histórico da doença. TEMPLETON (1967) obteve uma redução de 5\% na infecção por T. barclayana com aplicação tardia do Oxicarboxina. WHITNEY (1977) demonstrou que Fentin-hidróxido, Benomil, Manebe e Clorotalonil, aplicados nos estádios de emborrachamento e emissão de panículas, se mostraram ineficazes no controle de $\boldsymbol{T}$. barclayana. TSUDA et al. (2006) realizaram estudos no Japão para verificar a melhor época de aplicação de Simeconazol na formulação granulada de 1,5\%. Os testes revelaram que a aplicação de Simeconazol granulado na dose de 450 a $600 \mathrm{~g} \mathrm{ha}^{-1}$ de i.a, em um período de uma a cinco semanas antes da excersão da panícula, foi eficiente no controle da cárie-do-grão do arroz. Além disso, esses testes revelaram que o controle da cárie-do-grão do arroz é ainda superior nos tratamentos realizados em um período de uma a duas semanas antes da excersão da panícula.

Aplicações de Carbendazin no início e nos períodos máximos de florescimento apresentaram controle eficiente da doença (HU \& XUE, 1987). Estudos realizados por HORNSBY et al. (2000) mostraram que Propiconazol, aplicado durante o estádio de emborrachamento do arroz, pode reduzir a severidade da cárie-do-grão em 88\%. COSTA et al. (2006) mostraram que o uso de diferentes produtos fungicidas controlam o patógeno, embora a aplicação tenha sido realizada tardiamente (com 5\% de panículas abertas), e possivelmente a aplicação deva ser realizada em préflorescimento, visando proteger a inflorescência durante a antese.

Ciência Rural, v.39, n.5, ago, 2009. 


\section{CONCLUSÃO}

O poder destrutivo da cárie-do-arroz, causada pelo fungo T. barclayana, na cultura do arroz irrigado, no Rio Grande do Sul, sugere a adoção de medidas de controle, permitindo que o potencial produtivo da cultura seja alcançado.

Medidas culturais têm demonstrado efeito limitado sobre o patógeno, uma vez que as condições ambientais, tais como temperatura, umidade relativa do ar e luminosidade, influenciam a germinação dos esporos e consequentemente o desenvolvimento da doença, enquanto medidas de controle químico ainda não podem ser recomendadas, pois não existem produtos registrados para as condições do Brasil. Nas últimas duas safras de verão, no Estado do Rio Grande do Sul, a incidência da cárie-do-arroz voltou a níveis normais, não ocorrendo altas severidades, porém o seu potencial destrutivo ainda preocupa, uma vez que ainda existe inóculo suficiente nas áreas problemáticas. Assim, na presença de cultivares sensíveis e de condições ambientais favoráveis, podem ocorrer novas epifitias nos próximos anos. Para minimizar essa possibilidade, os produtores de arroz irrigado do Estado devem trabalhar com cultivares menos susceptíveis, fertilização nitrogenada racional e, principalmente, semeadura na época recomendada, evitando assim a exposição da planta durante a antese, momento em que está mais propicia à infecção pelo patógeno.

\section{REFERÊNCIAS}

ATKINS, J. Rice Diseases of the Americas, a review of literature. Washington: Agriculture Handbook, 1974. n.448.

BEDENDO, I.P. Carvões. In: BERGAMIN, F.A. et al. Manual de fitopatologia. 3.ed. São Paulo: Ceres, 1995. v.2, cap 49, p.881-888.

CARRIS, L.M. et al. Nonsystemic bunt fungi Tilletia indica and T. horrida: a review of history, systematics and biology. Annual Reviews Phytopathology, Saint. Paul, v.44, n.5, p.5/1-5/20, 2006. Disponível em: <http://arjournals.annualreviews.org/doi/ abs/10.1146/annurev.phyto.44.070505.143402>. Doi: 10.1146/ annurev.phyto.44.070505.143402.

CARTWRIGHT, R.D. et al. Artificial inoculation of kernel smut of rice in Arkansas. Research Series, Arkansas Agricultural Experiment Station, n.453, p.107-110, 1996.

CARTWRIGHT, R.D.; LEE, F.N. Rice diseases. In: SLATON, N.A. (Ed.). Arkansas rice production handbook. Litlle Rock: Univ. of Arkansas Coop. Ext. Serv., 2001. Cap.5, p.87100. (Misc. Publ. 192).

CASTLEBURY et al. Phylogenetic analysis of Tilletia and allied genera in order Tilletiales (Ustilaginomycetes; Exobasidiomycetidae) based on large subunit nuclear rDNA sequences. Journal of Mycology, Lawrence, v.97 n.4, p.888900, 2005.
CHAHAL, S.S. et al. Relationship of different floral characteristics of rice genotypes with occurrence of kernel smut caused by Tilletia barclayana. Journal of Mycology and Plant Phytopathology, Punjab, v.33, n.2, p.217-220, 2003.

COSTA, I.F.D.; LENZ, G. Cárie do arroz (Tilletia barclayana). Santa Maria: UFSM, Centro de Ciências Rurais, 2006. 9p. (Boletim técnico,1).

COSTA, I.F.D. et al. Cárie do arroz. Santa Maria: UFSM, Centro de Ciências Rurais, 2006. 4p. (Boletim Técnico).

Del PONTE, E.M. (Ed.). Fitopatologia.net - herbário virtual. Porto Alegre: UFRGS, Departamento de Fitossanidade, Agronomia, 2007. Acessado em 12 set. 2008. Online. Disponível na Internet: http://www.ufrgs.br/agronomia/fitossan/ herbariovirtual.

DURAN, R.; FISCHER, G.W. The genus Tilletia. Washington: Botanical Gazette, 1961. 138p.

FAGERIA, N.K. et al. Growth and mineral nutrition of field crops. 2.ed. New York: M. Dekker, 1997. 624p.

FAGERIA, N.K.; SANTOS, A.B.D. Cultivo do arroz irrigado no Estado do Tocantins, EMBRAPA, 2004. Capturado em 22 mai. 2006. Online. Disponível na internet: http:// sistemasdeproducao.cnptia.embrapa.br/FontesHTML/Arroz/ ArrozIrrigadoTocantins/adubacao_calagem.htm\#nitrogenio.

FUNCK, G.R.D. Manejo de doenças do arroz irrigado e suas implicações no ambiente, 2008. Capturado em 02 mar. 2008. Online. Disponível na internet: http:// www.irga.rs.gov.br/index.php?action=meioambiente.

GROTH, D.; LEE, F. Rice diseases. In: SMITH, W.E.; DILDAY, R.H. (Ed.). Rice: origin, history, technology, and production. Hoboken, NJ,: John Wiley \& Sons, 2002. Cap.9, p.413-436.

HORNSBY, Q. et al. Management of kernel smut of rice with fungicides in Arkansas. In: RICE TECHNICAL WORKING GROUP, 28., 2000, Biloxi. Proceedings... Biloxi: Dept. of Agriculture, 2000. p.80.

HU, M.; XUE, T.P. Study on the occurrence of the kernel smut of rice caused by Neovossia horrida and its control. Acta Phytophylactica Sinica, Shangai, v.14, n.2, p.87-92, 1987.

IBGE. Estatística da produção Agrícola. Capturado em 21 Fev. 2008. Online. Disponível na internet: http:// www.ibge.gov.br/home/estatistica/indicadores/agropecuaria/lspa/ default.shtm

JISKANI, M.M. Diseases of rice - identification and management. Tandojam: Sindh Agriculture University, 2001. Capturado em 15 de Out. 2008. Online. Disponível na internet em: http://www.pakstoneconomist.com.

KRUGNER, T.L. Ação do ambiente sobre as doenças de plantas. Viçosa: Agronômica Ceres, 1978. V.1, p.215-226.

KUMAR, I. et al. Fertilizer levels and incidence of bunt disease in rice in India. International Rice Research Newsletter, Manila, v.3, n.4, p.5, 1978. 
LIANG, J. et al. Key factors influencing chlamydospore germination of rice kernel smut. Acta Phitophylacica Sinica, Beijing, v.30, n.4, p.343-346, 2003.

LIANG, J.N. et al. Factors influencing germination of chlamydospores of rice kernel smut. Acta Phytophylacica Sinica, Beijing, v.23, n.1, p.25-28, 1996.

MARUMOTO, T. Microbial nitrogen fixation and its availability to rice plants as revealed with the use of $15 \mathrm{~N}$ in Japan. Japan Agricultural Research Quarterly, Yatabe, v.20, n.2, p.108-114, 1986.

OU, S.H. Fungal diseases (Foliage diseases). In: OU, S.H. Rice diseases. 2.ed. Kew: Commonwealth Micological Institute, 1985. p.109-246.

PADWICK, G.W. Manual of rice diseases. Kew: Commonwealth Mycological Institute, 1950. 198p.

PADWICK, G.W.; KHAN, A. Notes on Indian fungi. Kew Imperial Mycological Institute: Mycological Papers, 1944. p.17.

PAN, X.X. et al. Studies on source of inoculum of kernel smut and its occurrence on hybridization rice. Acta Phytophylacica Sinica, Beijing, v.22, n.4, p.289-296, 1995.

PIMENTEL, G. et al. Genetic variability among isolates of Tilletia barclayana, T. indica and allied species. Mycologia, Bronx, v.90, n.6, p.1017-1027, 1998.

RAM, S. et al. Kernel Smut of rice: present status. International Journal of Tropical Plant Diseases, v.16, n.2, p.149-167, 1998.

REYES G.M. The black smut or bunt of rice (Oryza sativa L.) in the Philippines. Journal Agriculture, Philipp, v.4, p.241270, 1933.

RIBEIRO, A.S. Doenças. In: TERRES, A.L.; GALLI, J. Fundamentos para a cultura do arroz irrigado. Campinas: Fundação Cargill, 1985. p.205-250.

RODRIGUEZ, A. Carbones. In: LLÁCER, G. et al. Patología vegetal. 2.ed. Valencia: Phytoma, 1995. V.2, cap 26, p.865884.
SHARMA, R.C. et al. Kernel smut-a major constraint in hybrid seed production of rice and its remedial measures. Seed Res. Punjab, v.27, p.82-90, 1999.

SINGH, R.A. Source of inoculum and the epidemiology of bunt of rice. Riso, Slaton, v.25, p.77-80, 1975.

SLATON, N.A. et al. Effect of nitrogen fertilizer rate and method of application on yield and kernel smut of 'LaGrue' rice. In: NORMAN, R.J. et al. Rice research studies 2000. Fayetteville: Arkansas Agricultural Experiment Station, 2001. p.210-218.

SLATON, N.A. et al. Grain yield and kernel smut of rice as affected by preflood and midseason nitrogen fertilization in Arkansas. Agronomy Journal, Madison, v.96, n.1, p.91-99, 2004.

SOSBAI. Sociedade Sul-Brasileira de Arroz Irrigado. Arroz irrigado: recomendações técnicas da pesquisa para o Sul do Brasil. Santa Maria, 2005. 159p. il.

TAKAHASHI, Y. On Ustilago virens Cooke and a new species of Tilletia parasitic on rice plant. Botanical Magazine, Tokyo, v.10, n.2, p.16-20, 1896

TEMPLETON, G.E. Kernel smut of rice as affected by nitrogen. Arkansas Farm Research, Fayetteville, v.12, n.5, p.12, 1963.

TEMPLETON, G.E. Local infection of rice florets by the rice kernel smut organism, Tilletia horrida. Phytopathology, California, v.51, p.130-131, 1961.

TEMPLETON, G.E. Rice disease research. Rice Journal, New Orleans, v.70, n.7, p.28-30, 1967

TSUDA, M. et al. Optimal application timing of Simeconazole granules for control of rice kernel smut and false smut. Journal of General Plant Pathology, Springer, v.72, n.5, p.301304, 2006.

WEBSTER, R.K.; GUNNELL, P.S. Compendium of rice diseases. Saint. Paul, 1992. 86p.

WHITNEY, N.G. Effect of fungicide applications on kerne smut of rice. Plant Disease Reporter, Beltsville, v.61, n.5, p.379-381, 1977. 